\title{
Toponyms as a Gateway to Society
}

\author{
An Abui Case Study
}

\author{
Shaun Lim Tyan Gin \\ Independent Researcher, Singapore \\ L17ooo2@ntu.edu.sg
}

Francesco Perono Cacciafoco

School of Humanities, Linguistics and Multilingual Studies Programme, Nanyang Technological University, Singapore

fcacciafoco@ntu.edu.sg

\begin{abstract}
Abui is a Papuan language spoken in Alor Island, South-East Indonesia. Although there are rich studies on the Abui language and its structure, research on Abui toponymy, which aids the understanding of language, culture, and society, deserves greater attention. This paper analyzes features of Abui society through Abui toponyms collected using Field Linguistics and Language Documentation methods. It finds that, because place names communicate valuable information on peoples and territories, Abui toponyms reflect the agrarian lifestyle of Abui speakers and, more broadly, the close relationship that the people have with their landscape. Furthermore, Abui toponyms express positive traits in the Abui culture like kinship ties and bravery. Notwithstanding, like other pre-literate and indigenous societies, oral stories are commonly used to explain how places are named. This paper augments the existing Abui toponymic studies on the connection between names and the places they name and provides a deeper understanding of the Abui language, culture, and society.
\end{abstract}

\section{Keywords}

Abui language - Alor Island - toponymy - language documentation - ancient world 
Place names or toponyms, are inextricably connected with the history of a place. They commemorate the events of the past or the people that inhabited the place. Toponyms, as carriers of the past, not only help individuals develop a sense of attachment to places long after these events have happened (Helleland 2012), but also foster collective and communal identities, a point noted by the toponymist Laura Kostanski:

“[...] events and actions are remembered by place-names, in a way similar to buildings and inscriptions on walls. In this way, in their memorialization of actions and events, communities utilize toponyms as mnemonic devices for their collective identity"

KOSTANSKI 2016:421

On the linguistic front, toponyms too, conserve aspects of past languages, and thus, are valuable in the study of the history of languages. Toponyms preserve linguistic elements of the language(s) once spoken in the locality (Særheim 2011; Hedquist et al. 2014; Endo 2021) and because they retain parts of languages that might have disappeared elsewhere, "permit historical inferences about languages and the people who spoke them" (Campbell 2013:436). Toponyms, which have been around since the earliest settlers occupied a place, contain linguistic features or naming principles that do not exist in current languages or modern societies. Thus, a linguistic analysis of place names provides insights in the phonetic, semantic, morphosyntactic, and onomasiologic structures of toponyms (and their changes over time).

Moreover, as aforementioned, place names, through their commemorative and evocative functions, acquire cultural connotations and reflect the local culture and identity. In parts of Central America, indigenous place names are integral in creating a regional identity, as well as drawing tourists to see these sites. Kathryn Hudson notes that toponyms in such areas continue to be the "symbolic markers of cultural identities" (Hudson 2020:96) and simultaneously, a tool in initiating and interpolating sociocultural and political structures which promote tourism and socio-economic development. The diversity of toponymic practices utilized in naming places also indicate the various cultural values that are esteemed by different individuals; these beliefs in turn

* This paper was presented at the Asian Conference on the Ancient World, Beijing Normal University, China, and BNU-HквU United International College, Hong Kong on 29 January 2021. 
get embedded in the place names themselves (Jenjekwa \& Barnes 2017). The sociocultural and ecological nature of places also contribute to the place naming process in these areas. This not only highlights the intersection between diverse disciplines like Toponymy, Linguistics, Geography, Ecology, and Cultural Studies, but more importantly, illustrates how inhabitants describe and understand places through their awareness of linguistic, cultural, and ecological relationships between people and place - an approach known as toponymic ethnography - which is an increasingly innovative and multidisciplinary method used in Toponymy (Nash 2012; Nash 2015; Nash \& Low 2015; Hearn 2021).

For these reasons then, toponyms have been termed as "living fossils" of the study of language, history, and culture, and are particularly useful in describing the history of ethnic groups and changes in rural settlements (Zhao et al. 2020) because toponyms enable an understanding of societies, be they urban/rural, or newer/ancient.

In the thematic focus of this journal which studies the economic, social, and linguistic aspects of Old World and non-Eurocentric civilizations, an example of a rural context where the argument of toponyms being "living fossils" can be extended to is the Abui society. Located in Alor Island, South-East Indonesia, Abui is a Papuan language spoken by about 17,00o speakers (Kratochvíl et al. 2016a), who are known as the Abui people. Although there have been scholarly works on the Abui people and language, this paper aims to add to existing studies on Abui toponymy in shedding light on the Abui language, culture, and society. Consequently, this paper aims to answer the following question: what do Abui toponyms tell us about Abui society? Through extensive fieldwork involving Field Linguistics, Language Documentation, and Anthropological Linguistics, the authors analyze features of Abui society through its toponyms and ultimately providing a deeper understanding of the Abui language, culture, and society.

\section{What Is known about the Abui People, Language, History, and Culture?}

The word Abui, in the Abui language, means 'mountain' or 'enclosed space'. In Bahasa Malay, Abui refers to the Abui speakers who define their language as Abui tangà 'mountain language', and call themselves Abui lokù 'mountain people' (Kratochvíl 2007). The name of the people and language is explained by how Alor Island, where Abui speakers reside in, comprises a collection of hills. The entire interior of the island is referred to as abui 'mountains', 
thereby giving the name to the territory, language, and people (Kratochvil et al. 2016a). According to Abui oral traditions, the Abui people settled in Alor in ancient times. Some of them, later, moved to the Kabola territory in Alor Island, where they lived in caves in the mountains of Mainàng (Nicolspeyer 1940; Kratochvíl 2007).

The Abui language belongs to the Alor branch of the Alor-Pantar language family (Holton et al. 2012), a family of related Papuan languages (Klamer 2010). The Alor-Pantar language family, as shown in Figure 1, is divided into two branches: the Alor branch (which Abui falls under) and the Pantar branch, which spread on and are spoken on the islands of Alor and Pantar respectively (Klamer 2017).

Diary entries written in 1521 by Antonio Pigafetta are possibly the first known documentation of the people living on Alor Island. Pigafetta was an Italian officer on the ship of Juan de Elcano, who succeeded Captain Fernão de Magalhães after the latter's death on his round-the-world voyage (Koentjaraningrat 2007). Other records also indicate some contacts between the Hindu-Javanese sea Kingdom of Majapahit and natives of Alor Island (Hägerdal 2012). In the 16th century, the Portuguese established settlements in present-day East Timor. Due to the geographical proximity of Alor Island to East Timor, the Portuguese started conducting missionary activities in Alor Island from 1561 (Klamer 2010). During the 17th century, there was an intense rivalry between the Portuguese and Dutch for control over colonies and trade in the region. The Dutch conquered the former Portuguese stronghold of Solor in 1613 and settled in the nearby Flores Island. In 1836, the Portuguese, as a result of the continued Dutch attacks in Solor, moved to Kupang, West Timor. In 1859, the Portuguese and Dutch signed a treaty delineating a boundary between their territories and assigning Flores, Solor, and Alor Islands to

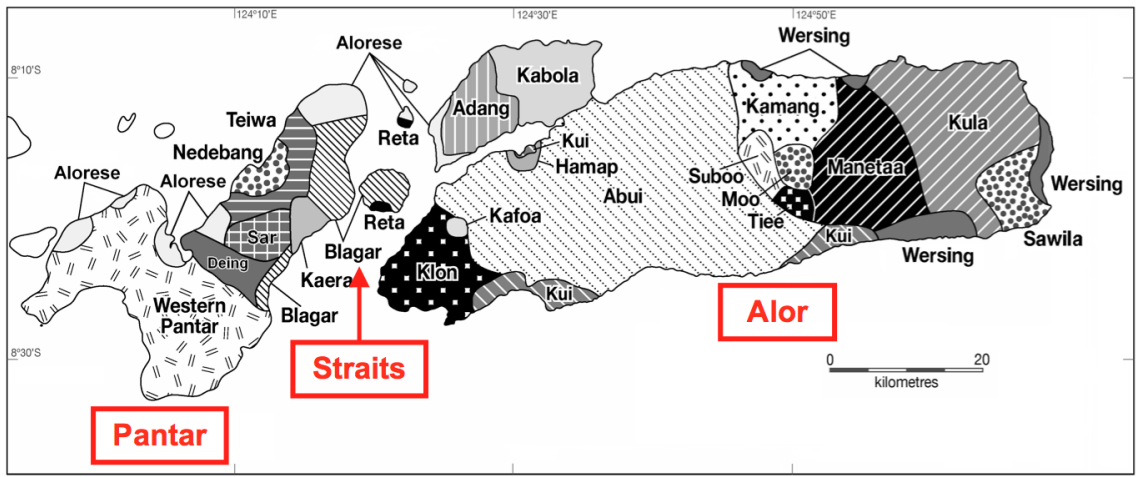

FIGURE 1 Linguistic situation in the Alor-Pantar Archipelago SOURCE: SCHAPPER \& HUBER 2012 
the Dutch. However, it was not until a 1914 ruling by the Permanent Court of Arbitration at the Hague that border issues were resolved (Fernandes 2015). For decades, the Dutch colonial presence in Alor Island remained limited; it was only in 1910 when Dutch Governor-General Van Heutz began a military campaign to bring local rulers and people under their administration (Klamer 2017). Friction between the Alor people and their colonizers culminated in a violent rebellion in 1917 and an uprising in September 1918 when the Abui people, angered by tax collection disputes, killed the Dutch-appointed Raja of Alor, Bala Nampira and his men (Stokhof 1984; Kratochvíl 2007). Further revolts were also recorded in 1942 and in 1945 (Van Galen 1945; Hägerdal 2010).

The Abui people and culture were first described by American anthropologist Cora DuBois in her 1944 book, The People of Alor: A Social-Psychological Study of an East Indian Island, compiled after her 18-month fieldwork in Alor Island. DuBois evaluated the island's ethnography, gathered the life histories of natives, and administered tests to uncover the personality of the Abui people living on Alor Island (Raybeck 2013). DuBois' study was the first research conducted under the basic personality structure framework (Moberg 2019), making her an eminent scholar in the field of culture and personality studies. Early research on the Abui people can also be found in Martha Nicolspeyer's work. Nicolspeyer, who travelled with DuBois, described the Abui social structure and recorded some Abui legends and words (Nicolspeyer 1940).

Presently, a strand of research on the Abui focuses on studying Abui oral traditions, an integral element of Abui culture. Abui myths and legends, known

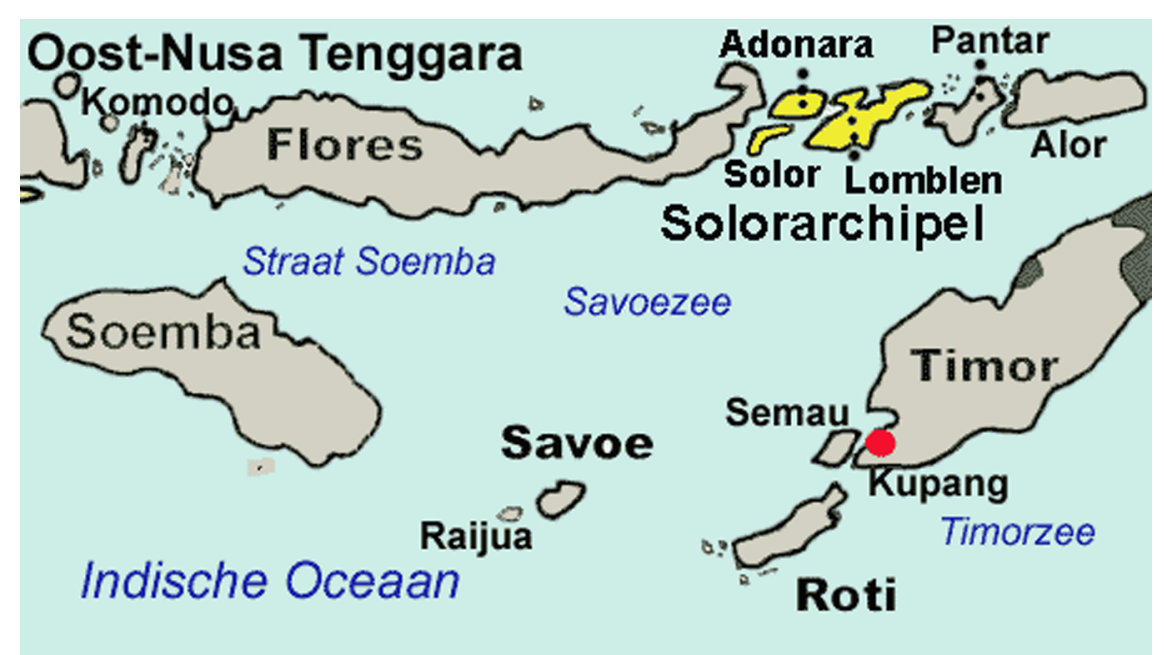

FIGURE 2 A map of Alor Island and its neighboring islands SOURCE: WIKIPEDIA, N.D. 
as tira, record historical events. These stories are deeply rooted in local oral history traditions and perpetuate the telling of myths to members of the community. The Abui people allude to the truthfulness of these legends by referencing how parts of the story occur in the physical landscape (i.e., rocks, caves, water bodies, places, and coastal areas) - many of these features still stand today (Kratochvíl et al. 2016b). Thus, the Abui tira plays a crucial function of enacting and reinforcing the lasting relationships that the people have with their landscape.

Unsurprisingly, oral traditions have been used to account for the origins of certain Abui place names and micro-toponyms. Perono Cacciafoco and Cavallaro recount the legend of a local god, Lamòling as told to them by Abui natives. There are eight toponyms and micro-toponyms in the story, and their etymological explanations are all derived from the Lamòling story. As an example, the place name Lamòling Bèaka 'bad Lamòling' or 'Lamòling the evil', was given to the place by the Abui people after the historical event where Lamòling offered to locals a meal consisting of a missing child's body. This led them to conclude that Lamoling was responsible for abducting and killing the child and the villagers plotted revenge on the god. The Abui people can indicate the exact position of this village today, which hitherto did not have a name before the event, in order to link the village to the monstrous act which they believed really happened there (Perono Cacciafoco \& Cavallaro 2017). Perono Cacciafoco's and Cavallaro's 2018 study follows up on the legend of Lamòling. The authors trace how this story has evolved and changed from ancient times to the colonial era, when the Dutch introduced Christianity in Alor Island and parts of the story were modified according to Christian elements. For example, Lamòling was eventually banished to Pakulang Hieng by Lahatàla, who in this version became the Christian God. In this sense, the legend mirrors the Christian story of Lucifer, the most beautiful angel of heaven, who rebelled against God and was sunk to hell. Additionally, the authors also studied the significance of sacred objects and rituals in this myth to the Abui people (Perono Cacciafoco \& Cavallaro 2018).

Although Toponymy as a field of study has important contributions to the linguistics, culture, and society of any place and language, Abui toponomy is rather an under-studied area. Presently, most research on Abui focuses on the language and structure of the Abui language (Klamer \& Kratochvíl 2006; Klamer \& Kratochvíl 2010; Kratochvíl 2011a; Kratochvíl 2011b; Holton et al. 2012; Kratochvíl 2014; Kratochvíl and Delpada 2015; Klamer 2017; Saad et al. 2019; Klamer \& Saad 2020; Saad 2020). Notwithstanding, there have been some studies on Abui toponymy. At the linguistic level, Abui toponyms have been approached according to an experimental methodology, 
which combines Historical Linguistics, Etymology, Historical Semantics, and Historical Phonetics with Field Linguistics and Language Documentation, to analyze toponyms. This analysis is done with the aim of reconstructing the "right" etymology of the place name and highlighting the original naming process, the subsequent process of paretymology, ${ }^{1}$ and the relationships of toponyms with other place names and words from the language used to name these places (Perono Cacciafoco et al. 2015). The authors conducted a linguistic analysis on a series of apparently related place names (Afena Hapong and Afena Hietang) and a toponymic system (i.e., a group of toponyms connected with each other: Lamang Tăha, Lamang Uwo, Lalamang, and Laaling). Results illustrate a semantic narrowing in the Abui word used to describe village and morphological elements of the Abui language (for example, reduplication). A linguistic analysis, beyond constructing the remote origins of these toponyms and undocumented languages, also sheds light on the 'speakers' interpretation of the environment, their perception of landscape, and their description of territory" (Perono Cacciafoco et al. 2015:45).

Additionally, Kratochvíl et al. (2016a) note the origins and functions of Abui toponyms. Through their fieldwork and mapping of Abui toponyms, they have shown that Abui place names are largely native, transparent, and derived from the agricultural and horticultural crops grown around the area. Such observations are also supported in Lim \& Perono Cacciafoco (2020a), who highlight the transparency of Abui toponyms; they are named after plants cultivated in the area with the topmost toponymic sources being mea 'mango', wata 'coconut', and kanaai 'canarium'. Kratochvíl et al. (2016a) also note that Abui toponyms serve important social functions, such as affirming kin relations, staking out land claims and rights, and verifying the veracity of certain ancestral myths such as the legend of Lamòling as noted elsewhere (for instance, Perono Cacciafoco \& Cavallaro 2017).

Consequently, this study aims to contribute to the small but growing number of studies on Abui toponymy. As previously noted, the study of place names facilitates greater knowledge about the language, history, culture, and society of places. In line with the linguistic value and sociocultural and historical functions of toponyms, this paper analyzes a corpus of Abui toponyms to discover facets of Abui society which may have so far remained obscure.

1 According to Perono Cacciafoco et al. (2015), paretymology refers to the process where a word is etymologically reinterpreted due to similarities (in form, meaning or sound) with other words, deviating from the original form or meaning. 
The authors conducted field work to collect original data and utilized existing field work reports. Over 50 toponyms were collected as a sample of analysis under a previous study (Lim \& Perono Cacciafoco 2020a) to determine the relationship(s) between plant species and place names in Alor Island, as well as the tira connected with the toponymic naming process. Working together with Abui speakers and their Abui consultant, Mr. Benidiktus Delpada, the authors collected toponymic data, documented, and double-checked these toponyms for their linguistic structure. Through an exploration of the Abui territory, the authors also engaged in map drawing and interviews with Abui people to document oral traditions associated with these toponyms.

Thereafter, the authors adopted an Intensive Toponymy approach, a method described by toponymist Jan Tent as "answering questions on the etymology and meaning of particular toponyms" (Tent 2015:66). Tent likens this idea to writing the "biography" of a toponym (Tent 2015:67-68) by answering wh-questions about the place name. In analyzing the corpus of toponyms, the authors sought to ascertain the following: (1) What does the name mean (by looking at the toponym, its English gloss, and possible Abui roots), (2) Why was the place given that name (through a study of the toponym's etymology and surrounding landscape use), and (3) Where is the place located at (via a geographical analysis of the toponym's location and type, for instance, whether it was a town, village, settlement, etc.)

In this study, the authors utilize the toponymic data collected via Field Linguistics, Language Documentation, and Anthropological Linguistics methods, and through an emphasis on analyzing the toponyms' roots, landscape use, as well as the myths and legends connected with these place names, draw out themes in answering the question: what do Abui toponyms tell us about Abui society? In the next section, the authors examine three broad themes gleaned from analyzing the toponyms.

Themes from the Analysis

\subsection{Agrarian Nature of Society}

Kratochvil, in his 2007 doctoral dissertation, A Grammar of Abui, notes that Abui speakers are mainly farmers, like other inhabitants of Alor. The importance of agriculture and horticulture is mirrored in Abui toponyms. Over 40 of the toponyms collected are named after crops cultivated around the locality, as shown in Table 1. This is reinforced in Kratochvíl et al. (2016a) where the 


Crop Toponym count

$\begin{array}{ll}\text { mea 'mango' (mangifera indica) } & 9 \\ \text { kanaai 'canarium' (canarium indicum) } & 8 \\ \text { wata 'coconut' (cocos nucifera) } & 6 \\ \text { tamal 'tamarind' (tamarindus indica) } & 5 \\ \text { kalang 'cussambium tree' (schleichera oleosa) } & 4 \\ \text { muur 'lemon' (citrus limon) } & 4 \\ \text { daa 'cassava' (manihot esculenta) } & 2 \\ \text { fiyaai 'candlenut' (aleurites moluccanus) } & 2 \\ \text { soong 'jackfruit' (artocarpus heterophyllus) } & 2 \\ \text { ayak 'rice' (oryza sativa) } & 1\end{array}$

authors find that the majority of Abui place names have some relationship to land use, be they horticulture, agriculture, or forestry, and are etymologically transparent. More generally, this toponymic naming practice is also reflective of the descriptive naming, where places are named after nearby flora and fauna (Rennick 2005; Perono Cacciafoco \& Tuang 2018; Lim \& Perono Cacciafoco 202ob).

As shown in Table 1, the most common toponymic sources are mea 'mango', kanaai 'canarium', wata 'coconut', and tamal 'tamarind'. A surprising find is that although ayak 'rice' and daa 'cassava' are regarded as staples in the Abui diet (Kratochvíl 2007), a total of three toponyms are named after these two crops in the database. The toponyms in the database mostly name fields, villages, and settlements in North and North-Central Alor. It is worth noting though that some place names are common throughout Alor Island (there are three villages named Wata Meelang 'coconut village': one in North-Central Alor, another in Central-West Alor, and the last in West Alor).

Most toponyms describe basic landscape concepts such as villages, resting places, jungles, and plains, supporting previous findings on the transparency of Abui toponyms (Kratochvíl et al. 2016a). The authors found that almost every crop had a village named after it. Some examples of crop-based toponyms describing landscape features include:

- Mea Meelang 'mango village'

- Mea Lulang 'lit. mango resting place'

- Wata Meelang 'coconut village'

- Wata Fuui 'lit. coconut plain'

- TamalAtiing 'jungle of tamarind (tree)' 
- Muur Meelang 'lemon village'

- Soong Meelang 'jackfruit village'

- Kalang Meelang 'cussambium village'

- Kalang Maasang 'cussambium sanctuary'

In these examples, Abui toponyms appear to mirror the structure of English toponyms, which comprise a specific + generic element (e.g., Tweed River, Mount White) (Tent 2020). Often, the specific element of the toponyms, as seen above, assumes the name of the horticultural or agricultural source while the generic element refers to the landscape category named after the crop (e.g., Mea Meelang 'mango village', Mea Lulang 'lit. mango resting place', Wata Fuui 'lit. coconut plain').

Abui toponyms also describe characteristics of crops cultivated in the locality. The close relationship that the Abui people share with agricultural and horticultural sources cultivated in the landscape is evident in how they have attached qualities to these crops - both positive and negative. Among others, these descriptors elucidate attitudes, traits, numbers, colors, smells, tastes, and the physical appearance of the crop. Because of the lasting relationships and significance that the Abui people attach to the physical landscape, including plants and animals, the crop becomes personified; it is almost as though they have human-like features and can be depicted using these characteristics, which in turn, gets embedded in the place name. Toponyms serve as descriptors of the crops and by implication, represent features of the physical and sociocultural landscapes where these crops are cultivated, as is observed in the following toponyms:

- Mealati

- Mea Kilikil

'twisted mango'

- Mea Munuma

'idle mango'

- Wata Kiika

'lit. fragrant mango'

- Kanaai Loohu

'red coconut'

- Kanaai Sua

'long canarium'

- Kanaai Kaai

- Tamal Raloowang

- Tamal Pataqa 'triplet canarium' 'gluttonous (to eat) canary (nut)' 'sweet tamarind' 'thin tamarind'

There are also instances where agricultural and horticultural species have been used as distance markers, indicating the distance of the place in relation to the particular crop. This is reminiscent of how toponyms help people find their way through indicating spatial and distal characteristics of the place name to the place's surroundings. This is especially evident in indigenous and aboriginal contexts which might not have maps or modern cartographical 
systems. As the anthropologist of the Navajo, Richard F. Van Valkenburgh notes, place names and their stories are:

replete with accounts of natural features, locations, distances ... To the Navajo, these details are important alike because of their sacred associations and because of their practical significance: to a people who did not write they served as the equivalent of our maps, and they guided the Navajo to sites for hunting and for gathering plant foods, ceremonial plants, minerals, and other objects used in rituals.

VAN VALKENBURGH (1974:17-18)

Some Abui toponyms that point to the distance of the place from the related species include:

- Mea Malieng Pe'lit.

- Kanaai Pea

- Kanaai Awee Pe

'near a type of mango' 'nearby canarium' 'near top of canarium'

- KanaaiTukuPe 'near canarium stump'

In all these examples, mea 'mango' and kanaai 'canarium' trees are found within proximity of the fields they name - proof that Abui toponyms name and describe the location, direction, position, or distance in relation to other places and/or features - these spaces in the Abui context, are that of neighboring plants and crops, ostensibly due to the agrarian nature of Abui society. This is seen by the use of pe or pea, an Abui word describing the condition of nearness, in these toponyms that reflect the distance between the toponym and the crop.

\subsection{Social Values}

Kratochvíl et al. (2016a) observe that Abui toponyms have crucial social functions, such as affirming kin relations. This is observed in the roots of the place name itself. Consider the following examples:

- Fiyaai Lelang 'lit. candlenut kins'

- Daalelang 'lit. cassava kins'

In the above examples, one can observe the inclusion of the morpheme, lelang, which denotes familial ties. Lelang, according to Abui natives, means 'allied congenial kin groups or relatives'. In turn, lelang can be parsed as le 'interrogative' + lang 'a hand-made set of wood', which can be used to hang gong instruments or be placed at the border of a field to mark it. People located in the places where fyaai 'candlenut' or daa 'cassava' grew could be related to each other or have a common ancestor. That there is a root in the toponym, 
lelang, referring to kin groups highlights that Abui place names can be used explicitly to attest to kinship ties.

An interesting place name is Tamal Liiki 'cruel tamarind'. This toponym appears to have an unclear etymology; Tamal Liiki can be parsed into tamal 'tamarind' and liik/i 'platform', which is inconsistent with its gloss of 'cruel tamarind'. Additionally, the adjective 'cruel', connected with a plant, does not mean anything at a first glance. However, an explanation for this toponym can be derived from local oral traditions and the cultural values that the Abui people imbue in this name. Our consultant and the Abui people postulate that this place was named after a local warrior who built a house and lived under a tamarind tree around Tamal Liiki, and the morpheme liiki would symbolize the character of this warrior. Hence, it appears that the adjective 'cruel', in this context, has a somewhat positive connotation, since the Abui people believed that the Abui warriors like the warrior of living at Tamal Liiki had to be 'cruel' or 'fierce' towards their enemies to protect their people and lands. At the same time, the analysis of Tamal Liiki demonstrates the value of bravery and strength that the Abui place amongst their people as the place name celebrates a brave warrior who once resided in the area.

\subsection{Tales and Knowledge Production}

While most toponyms are transparent, there were certain places which stood out as anomalies. In these locations, there was an absence of the very crop that the place was purportedly named after. Confronted with such a gap, the Abui natives used oral stories to explain how these places derived their names and meanings. In the example of Mea Kilikil 'idle mango', there is only one mango tree in this area today. According to the Abui people, this place got its name after a hiker who was feeling tired after a long journey and decided to rest under the only mango tree that grew in Mea Kilikil. Another case is Wata Meelang 'coconut village'. Although there are only two or three coconut trees observed in Wata Meelang, locals explain that this village is named to commemorate the local religious practice of roasting rice in a coconut. Another story behind the naming origins of Wata Meelang was that a local religious leader used to live under one of the few coconut trees in the village. Both toponymic stories relate to religious people and practices and share similarities to other stories of how religion in the Abui culture influences place names and who they are as a people, i.e., their foundational myths (Perono Cacciafoco \& Cavallaro 2017; Perono Cacciafoco \& Cavallaro 2018). Locals also use legends to explain how etymologically obscure places are named. Daafuku is one such example. The place is glossed as 'a traced lane in the forest where cassavas grow'; daa refers to 'cassava' while fuku means 'wild pig's or deer's traced lane 
to be trapped (by hunters)'. Although it is unknown how wild pigs or deer are associated with Daafuku, one plausible theory is that local men, when hunting for wild pigs or deer, hide in the bush of the cassava plants at Daafuku, before shooting an arrow at their prey.

The fact that a number of these toponyms can be explained by the Abui people using oral stories, be they revealing the traits of the crops grown in the area like Tamal Liiki 'cruel tamarind' or conversely, rationalizing the lack of plant species found in the place like Mea Kilikil 'idle mango' and Wata Meelang 'coconut village' or even reconstructing etymologically obscure place names like Daafuku provide an outlook on how the Abui people produce knowledge via these oral traditions. These oral traditions can explain certain oddities and intersect with other crucial elements to the Abui - nature, ecology, animals, kinship, religion - all of which feature in these stories. This is reminiscent of Absolon's characterization of indigenous knowledge, which she describes as lying:

in our stories and narratives and within our oral traditions. It exists in our relationships to one another and to all of creation. Indigenous knowledge exists in the animals, birds, land, plants, trees and creation. Relationships among family and kinship systems exist within human, spiritual, plant, and animal realms.

ABSOLON 2010:81-82

\section{$5 \quad$ Conclusions}

In the final analysis, the study of Abui toponyms allows a great deal to be uncovered about the language, culture, and society of the natives. Perono Cacciafoco et al. (2015) noted linguistic elements, particularly phonetic, semantic, and morphological rules of the Abui language through the study of Abui toponyms. In this study, an etymological analysis of Abui toponyms shows that place names are largely transparent and named according to a crop (specific element) and landscape category (generic element). Like other undocumented languages and case studies (for an example, see Brown 2008), Abui toponyms, through the morpheme pe or pea, serve as distal and spatial markers in marking the distance between the locality and the crop grown in the local landscape. At a societal and cultural level, Abui toponyms allude to cultural values prized by the locals such as kinship ties and bravery. These standards are explicitly encoded in the words and roots of the toponym (e.g., Fiyaai Lelang and Daalelang) or the stories behind etymologically obscure 
place names like Tamal Liiki. Notwithstanding, a central theme of this paper has been the role of oral traditions in the production of knowledge in Abui society. Most toponyms have stories connected with them and the Abui people use tira to explain what would otherwise seem as mysterious (in the cases where very little or no crops are grown in the area like Mea Kilikil or Wata Meelang) or at first glance, etymologically obscure (Tamal Liiki and Daafuku). The Abui case study is thus a useful case in demonstrating how toponyms reflect the characteristics of space and support emotional ties (Jordan 2014); Abui toponyms describe the physical and natural landscapes and the economic functions of a place. A study of place names with a lens of how they reveal spatial attributes, in Jordan's words, "highlight in this way aspects that seemed important to the people who named the place" (Jordan 2014:22). Moreover, oral stories serve identity-building, knowledge-construction, and heritage-carrier roles. To integrate Jordan's argument with Abolson's poignant quote, these stories remind the Abui people of everything important relationships to one another and creation; animals, land, and especially their crops, relationships among families, religion, and systems that exist within the human, spiritual, plant, and animal realms, which ultimately facilitates emotional ties between the community and place.

\section{References}

Absolon, Kathy (2010). Indigenous Wholistic Theory: A Knowledge Set for Practice. First Peoples Child \& Family Review: An Interdisciplinary Journal Honouring the Voices, Perspectives, and Knowledges of First Peoples through Research, Critical Analyses, Stories, Standpoints and Media Reviews 5 (2), pp. 74-87.

Brown, Penelope (2008). Up, Down, and Across the Land: Landscape Terms, Place Names, and Spatial Language in Tzeltal. Language Sciences 30 (2-3), pp. 151-181.

Campbell, Lyle (2013). Historical Linguistics: An Introduction. 3rd ed. Edinburgh: Edinburgh University Press.

Endo, Mitsuaki (2021). Geographical Distribution of Certain Toponyms in the Samguk Sagi. Anthropological Science 129 (1), pp. 35-44.

Fernandes, Clinton (2015). West Timor. In: P. R. Bartrop and S. L. Jacobs, eds, Modern Genocide:The Definitive Resource and Document Collection, Santa Barbara, California: ABC-CLIO, pp. 852 .

Hägerdal, Hans (2010). Van Galen's Memorandum on the Alor Islands in 1946: An Annotated Translation with an Introduction (Part 1). HumaNetten 25, pp. 14-44.

Hägerdal, Hans (2012). Lords of the Land, Lords of the Sea: Conflict and Adaptation in Early Colonial Timor, $1600-1800$. Leiden: KIT Lv Press. 
Hearn, Kyle P (2021). Mapping the Past: Using Ethnography and Local Spatial Knowledge to Characterize the Duero River Borderlands Landscape. Journal of Rural Studies 82, pp. 37-53.

Hedquist, Saul L, Koyiyumptewa, Stewart B, Whiteley, Peter M, Kuwanwisiwma, Leigh J, Hill, Kenneth C, and Ferguson, Thomas J (2014). Recording Toponyms to Document the Endangered Hopi Language. American Anthropologist 116 (2), pp. 324-331.

Helleland, Botolv (2012). Place Names and Identities. Oslo Studies in Language 4 (2), pp. 95-116.

Holton, Gary, Klamer, Marian, Kratochvíl, František, Robinson, Laura C, and Schapper, Antoinette (2012). The Historical Relations of the Papuan Languages of Alor and Pantar. Oceanic Linguistics 51 (1), pp. 86-122.

Hudson, Kathryn M. (2020). The Consequences of Names: Archaeology, Identity, and Tourism in Contemporary Mesoamerica. In: L. Caiazzo, R. Coates and M. Azaryahu, eds, Naming, Identity and Tourism, Newcastle upon Tyne: Cambridge Scholars Publishing, pp. 79-98.

Jenjekwa, Vincent, and Barnes, Lawrie (2017). The Transition from KwaMudzviti to the Town of Mupandawana: A Toponymic Perspective. Nomina Africana $3^{1}$ (2), pp. 127-139.

Jordan, Peter (2014). The Meaning of Bilingual Naming in Public Space for the Cultural Identity of Linguistic Minorities. Review of Historical Geography and Toponomastics 9 (17-18), pp. 21-24.

Klamer, Marian (2010). A Grammar of Teiwa. Berlin: Mouton de Gruyter.

Klamer, Marian (2017). The Alor-Pantar Languages: Linguistic Context, History and Typology. In: M. Klamer, ed, The Alor-Pantar Languages: History and Typology. 2nd ed, Berlin: Language Science Press, pp. 1-48.

Klamer, Marian, and Kratochvíl, František (2006). The Role of Animacy in Teiwa and Abui (Papuan). In: Proceedings of the 32nd Annual Meeting of the Berkeley Linguistics Society 2006, Berkeley, California: Berkeley Linguistics Society and the Linguistics Society of America, pp. 59-70.

Klamer, Marian, and Kratochvíl, František (2010). Abui Tripartite Verbs: Exploring the Limits of Compositionality. In: J. Wohlgemuth and M. Cysouw, eds, Rara and Rarissima: Documenting the Fringes of Linguistic Diversity, Berlin: Mouton de Gruyter, pp. $185^{-210 .}$

Klamer, Marian, and Saad, George (2020). Reduplication in Abui: A Case of Pattern Extension. Morphology 30, pp. 311-346.

Koentjaraningrat, ed. (2007). Villages in Indonesia. Jakarta and Kuala Lumpur: Equinox Publishing, pp. 1-3.

Kostanski, Laura (2016). Toponymic Attachment. In: C. Hough, ed, The Oxford Handbook of Names and Naming, Oxford: Oxford University Press, pp. 412-426. 
Kratochvíl, František (2007). A Grammar of Abui, Dissertation, Department of Linguistics, Leiden University.

Kratochvíl, František (2011a). Discourse-Structuring Functions of Abui Demonstratives. In: F. H. Yap and J. Wrona, eds, Nominalization in Asian Languages: Diachronic and Typological Perspectives, Volume 2. Amsterdam and Philadelphia: John Benjamins, pp. 761-792.

Kratochvíl, František (2011b). Transitivity in Abui. Studies in Language 35 (3), pp. 588-635.

Kratochvíl, František (2014). Differential Argument Realization in Abui. Linguistics $5^{2}(2)$, pp. 543-6o2.

Kratochvíl, František, and Delpada, Benidiktus (2015). Definiteness and Specificity in Abui. In: Proceedings of 2nd International Workshop on Information Structure of Austronesian Languages 2015, Tokyo: Research Institute for Languages and Cultures of Asia and Africa (ILCAA), Tokyo University of Foreign Studies, pp. 179-208.

Kratochvíl, František, Delpada, Benidiktus, and Perono Cacciafoco, Francesco (2016a). Abui Landscape Names: Origin and Functions. Onoma 51, pp. 75-111.

Kratochvíl, František, Delpada, Benidiktus, Siao, Rachel, Ng, Xiao Yan, Kelly, Joan M, and Dang, Mai Trang (2016b). Children of Mon Mot-Documentation of a tira Legend of the Abui Community (Eastern Indonesia). In: Proceedings of the 22nd International Conference on Virtual System \& Multimedia (VSMM) 2016, New York: IEEE (Institute of Electrical and Electronics Engineers) Xplore, pp. 1-7.

Lim, Shaun Tyan Gin, and Perono Cacciafoco, Francesco (2020a). Plants and Place Names: A Case Study of Abui Toponymy. Review of Historical Geography and Toponomastics 15 (29-30), pp. 121-142.

Lim, Shaun Tyan Gin, and Perono Cacciafoco, Francesco (2020b). Then and Now: A Comparative Historical Toponomastics Analysis of Station Names in 2 of Singapore's Mass Rapid Transit (MRT) Lines. Urban Science 4 (3), 37.

Moberg, Mark (2019). Engaging Anthropological Theory: A Social and Political History. 2nd ed. London: Routledge.

Nash, Joshua (2012). An Insular Toponymy: Place-Naming on Dudley Peninsula, Kangaroo Island. Transactions of the Royal Society of South Australia 136 (2), pp. $67-98$.

Nash, Joshua (2015). Island Placenaming and Insular Toponymies. Names: A Journal of Onomastics 63 (3), pp. 146-157.

Nash, Joshua, and Low, Mitchell (2015). Language and Place-Knowledge on Norfolk Island. Ethnos: Journal of Anthropology 8o (3), pp. 385-408.

Nicolspeyer, Martha Margaretha (1940). De sociale structuur van een Aloreesche bevolkingsgroep. Rijswijk: V.A. Kramers. 
Perono Cacciafoco, Francesco, and Cavallaro, Francesco Paolo (2017). The Legend of Lamòling: Unwritten Memories and Diachronic Toponymy through the Lens of an Abui Myth. Lingua: An International Review of General Linguistics 193, pp. 51-61.

Perono Cacciafoco, Francesco, and Cavallaro, Francesco Paolo (2018). Lamòling Bèaka: Immanence, Rituals, and Sacred Objects in an Unwritten Legend in Alor. Religions $9(7), 211$.

Perono Cacciafoco, Francesco, Cavallaro, Francesco Paolo, and Kratochvíl, František (2015). Diachronic Toponomastics and Language Reconstruction in South-East Asia According to an Experimental Convergent Methodology: Abui as a Case-Study. Review of Historical Geography and Toponomastics 10 (19-20), pp. 29-47.

Perono Cacciafoco, Francesco, and Tuang, Shu Qi (2018). Voices from the Streets: Trends in Naming Practices of Singapore Odonymy. Review of Historical Geography and Toponomastics 13 (25-26), pp. 9-30.

Raybeck, Douglas (2013). Cora DuBois. In: R. J. McGee and R. L. Warms, eds, Theory in Social and Cultural Anthropology: An Encyclopedia, Thousand Oaks, California: SAge Publications, pp. 203-206.

Rennick, Robert (2005). How to Study Placenames. Names: A Journal of Onomastics 53 (4), pp. 291-308.

Saad, George (2020). Abui. In: A. Schapper, ed, The Papuan Languages of Timor, Alor and Pantar, Volume 3. Berlin and Boston: Mouton de Gruyter, pp. 269-346.

Saad, George, Klamer, Marian, and Moro, Francesca (2019). Identifying Agents of Change: Simplification of Possessive Marking in Abui-Malay Bilinguals. Glossa: A Journal of General Linguistics 4 (1), 57.

Særheim, Inge (2011). Toponyms and Language History - Some Methodological Challenges. In: Proceedings of the 24th International Congress of Onomastic Sciences 2011, Barcelona: Onomàstica Biblioteca Tècnica de Política Lingüística, pp. $1403-1408$.

Schapper, Antoinette, and Huber, Juliette (2012). State-of-the-art in the Documentation of the Papuan Languages of Timor, Alor, Pantar, and Kisar: A Bibliography. Wacana: Journal of the Humanities of Indonesia 14 (2), pp. 370-404.

Stokhof, Wim A L (1984). Annotations to a Text in the Abui Language (Alor). Bijdragen tot de taal-, land- en volkenkunde (Journal of the Humanities and Social Sciences of Southeast Asia) 140 (1), pp. 106-162.

Tent, Jan (2015). Approaches to Research in Toponymy. Names: AJournal of Onomastics 63 (2), pp. 65-74.

Tent, Jan (2020). Simplex Generic Toponyms in Four English-Speaking Jurisdictions. Names: A Journal of Onomastics 68 (1), pp. 17-31.

Van Galen, G A M (1945). Memorie van Overgave van den Fundgeerend Controleur van Alor, Koepang (unpublished manuscript). 
Van Valkenburgh, Richard Fowler (1974). Navajo Sacred Places. In: C. Kluckhohn, ed, American Indian Ethnohistory, Indians of the Southwest: Navajo Indians, Volume 3. New York: Garland Publishing Inc., pp. 9-199.

Wikipedia (n.d.).Alor Island. https://en.wikipedia.org/wiki/Alor_Island Wikipedia (n.d.). Solor Archipelago. https://en.wikipedia.org/wiki/Solor_Archipelago. Zhao, Fei, Yao, Fu, Guize, Luan, Sujin, Zhang, Jingzhi, Cai, Jieyu, Ding, Jiangkang, Qian, and Zhiqiang Xie (2020). Spatial-Temporal Characteristic Analysis of Ethnic Toponyms Based on Spatial Information Entropy at the Rural Level in Northeast China. Entropy 22 (4), 393. 